are less likely to be diagnosed with OSA, despite having higher average BMls, suggests that a lack of symptom awareness in these populations may be leading to delayed presentation or nonpresentation to primary care, or even a systematic under-diagnosis of OSA in these groups by GPs. Alternatively it could be that there is a true reduction in prevalence of OSA with increasing levels of deprivation, but this seems unlikely given evidence on this association from research groups in other countries, and the well-known associations between deprivation and adverse health outcomes. ${ }^{10-12}$ This may indicate a need for health campaigns to publicise the condition, its symptoms and treatment options, targeted at people from the more deprived sectors of society.

The authors report that the evident reduction in OSA prevalence with increasing age could be secondary to discrimination or a focus on other co-morbidities in the elderly. ${ }^{9}$ This is a possibility, and given the impact on quality of life and the potential effects of conditions associated with OSA, investigation and diagnosis should not be delayed or ignored in primary care. Another explanation is that these OSA-associated diseases - and the mortality linked with them - may be causing the fall in OSA prevalence as age increases, as observed in this study.

This study by Wall and colleagues ${ }^{9}$ gives pointers to future research on OSA, as well as illustrating the research potential of large databases derived from electronic primary care records. ${ }^{13}$ Given the restricted age-range included in this study's target population, the strongly predictive factor of $\mathrm{BMI}$, and the rapidly rising obesity rates amongst younger age-groups in the UK, additional studies should be carried out to evaluate the contribution of obesity to OSA in people aged under 50. This may be especially significant for childhood OSA sufferers, considering the current childhood obesity epidemic in the UK and elsewhere. Further research is also required to investigate the apparent counter-intuitive findings in this paper regarding the association of OSA with socio-economic status and age.

Acknowledgements The Department of Primary Care \& Public Health at Imperial College London is grateful for support from the NW London NIHR Collaboration for Leadership in Applied Health Research \& Care (CLAHRC), the Imperial NIHR Biomedical Research Centre, and the Imperial Centre for Patient Safety and Service Quality (CPSSQ).

Conflicts of interest The authors declare that they have no conflicts of interest in relation to this article.
Contributorship Ravi Parekh and Edward Green wrote the manuscript. Professor Azeem Majeed provided feedback, guidance, critical review and revision of the manuscript.

Commissioned article; not externally peer-reviewed; accepted 11th September 2012 online 22nd October 2012

(C) 2012 Primary Care Respiratory Society UK. All rights reserved

http://dx.doi.org/10.4104/pcrj.2012.00091

Prim Care Respir J 2012; 21(4): 361-362

\section{References}

1. Punjabi N. The Epidemiology of Adult Obstructive Sleep Apnea. Proc Am Thorac Soc 2008:5:136-43. http://dx.doi.org/10.1513/pats.200709-155MG

2. Davies RJO, Stradling JR. The epidemiology of sleep apnoea. Thorax 1996;51(Supp 2):S65-S70. http://dx.doi.org/10.1136\%2Fthx.51.Suppl_2.S65

3. Peppard PE, Young T, Palta M, Skatrud J. Prospective study of the association between sleep-disordered breathing and hypertension. N Engl J Med 2000; 342(19):1378-84. http://dx.doi.org/10.1056\%2FNEJM200005113421901

4. Peker $Y$, Carlson J, Hedner J. Increased incidence of coronary artery disease in sleep apnoea: a long-term follow-up. Eur Respir J 2006;28:596-602. http://dx.doi.org/10.1183\%2F09031936.06.00107805

5. Punjabi NM, Polotsky VY. Disorders of glucose metabolism in sleep apnea. J Appl Physiol 2005;99(5):1998-2007.

http://dx.doi.org/10.1152\%2Fjapplphysiol. 00695.2005

6. Allender S, Rayner M. The burden of overweight and obesity-related ill health in the UK. Obesity reviews 2007;8:467-73. http://dx.doi.org/10.1111\%2Fj.1467-789X.2007.00394.x

7. Carter R, Watenpaugh DE. Obesity and obstructive sleep apnea: Or is it OSA and obesity? Pathophysiology 2008;15:71-7.

http://dx.doi.org/10.1016\%2Fj. pathophys.2008.04.009

8. Daltro C, Gregorio PB, Alves E et al. Prevalence and Severity of Sleep Apnea in a Group of Morbidly Obese Patients. Obesity Surgery 2007;17:809-14 http://dx.doi.org/10.1007\%2Fs11695-007-9147-6

9. Wall H, Smith C, Hubbard R. BMI and obstructive sleep apnoea in the UK: a crosssectional study of the over-50s. Prim Care Respir J 2012;21(4):371-6.

10. Grandner MA, Patel NP, Gehrman PR et al. Who gets the best sleep? Ethnic and socioeconomic factors related to sleep complaints. Sleep Med 2010;11(5):470-8. http://dx.doi.org/10.1016\%2Fj.sleep.2009.10.006

11. Li X, Sundquist $K$, Sundquist J. Socioeconomic status and occupation as risk factors for obstructive sleep apnea in Sweden: a population-based study. Sleep Med 2008;9(2):129-36. http://dx.doi.org/10.1016\%2Fj.sleep.2007.02.003

12. Reddy EV, Kadhiravan T, Mishra HK et al. Prevalence and risk factors of obstructive sleep apnea among middle-aged urban Indians: a community-based study. Sleep Med 2009;10(8):913-18. http://dx.doi.org/10.1016\%2Fj.sleep.2008.08.011

13. Majeed A. Sources, uses, strengths and limitations of data collected in primary care in England. Health Stat Q 2004:21:5-14.

\title{
Body mass index and obstructive sleep apnoea
}

See linked article by Wall et al. on pg 371

\section{*John Shneerson'}

1 Consultant Physician and Director, Respiratory Support and Sleep Centre, Papworth Hospital, Cambridge, UK

*Correspondence: Dr John Shneerson, Director RSSC, Papworth Hospital NHS Foundation Trust, Papworth Everard, Cambs, CB23 3RE, UK

Tel: +44 (0)1480 830541 Fax: +44 (0)1480 830620

E-mail: c/o Jane.warmer@papworth.nhs.uk
The article by Wall et al. in this issue of the $P C R J^{1}$ is one of the largest epidemiological studies ever to be carried out to assess the link between obstructive sleep apnoea (OSA) and obesity. Data were analysed from over a million subjects aged 50 years or over, and the body mass index (BMI) had been calculated in as many as $88 \%$. The aim of the study was to assess the prevalence of OSA and snoring, and to evaluate any correlation with BMI, age, gender and social class.

The study suffers from the disadvantage that the diagnosis of OSA was based purely on whether or not this was recorded as a Read computer code in the primary care notes. This clearly leaves scope for 
significant underestimation, since in most cases the diagnosis would only be made after referral to secondary care with a confirmatory sleep study and clinical assessment. OSA would be more likely to be recorded if it was clinically severe and typical in its presentation, and if the subject requested (or had access to) secondary care assessment. These factors may at least partly explain the lower prevalence of OSA in the lower socioeconomic group as well as the under-diagnosis overall. Only $0.6 \%$ of this population were found to have OSA, compared to previously ascertained figures of $4 \%$ in men and $2 \%$ in women. $^{2}$ In addition, OSA was almost four times more common in males than females in those with a raised $\mathrm{BMI},{ }^{1}$ but in reality this may be an exaggeration. Women with OSA are more likely to present with insomnia or fatigue than men and with less excessive daytime sleepiness, and are therefore less likely to be diagnosed using conventional criteria. ${ }^{3}$

Interestingly, there does appear to be a "dose-response" curve between BMI and the prevalence of OSA. The odds ratio for OSA was 27.4 if the BMl was greater than $40 \mathrm{~kg} / \mathrm{m}^{2}$ whereas it was only 6.5 if the BMI was $30-40 \mathrm{~kg} / \mathrm{km}^{2}$. This large increase may be real, but there may also have been inconsistencies in the measurement of BMI since there was no standardisation of how height or weight were recorded. There is also no information from the data about the interval between recording the BMI and the diagnosis of OSA. Other measurements of obesity such as the neck circumference have been found to be more closely linked to OSA than the BMI. ${ }^{4}$ Despite these reservations, the implication of this dose-response curve is that any reduction in weight in the obese may well have a significant therapeutic benefit in reducing the risk of developing OSA ${ }^{5}$ and probably its severity and complications such as hypertension, stroke or the obesity hypoventilation syndrome. ${ }^{6}$

The peak age prevalence of OSA in this report was between 60 and 64 years which is in line with other epidemiological studies. ${ }^{7,8}$ However, studies on individual patients with OSA have shown an increasing prevalence even in older age groups. This discrepancy is probably because older patients have fewer symptoms of OSA and are therefore less likely to be recognised in epidemiological studies. ${ }^{9}$ Apart from this, there are other reasons why OSA may be missed in older people. Firstly, they may not present to primary care as readily as younger subjects since they may feel that their OSA symptoms are part of normal aging. Secondly, they are less likely to be aware of some symptoms such as snoring. And thirdly, other co-morbidities may obscure the clinical features of OSA. For all these reasons, one of the messages of this study ${ }^{1}$ is that primary care physicians should be more alert to the possibility of OSA in older subjects presenting with unexplained symptoms - even if they are not the classical features of OSA seen in younger people such as snoring, excessive daytime sleepiness and witnessed apnoeas.

Many of the same considerations apply to the apparent underdiagnosis of OSA in the lower socioeconomic group. These patients may be reluctant to present to medical practitioners, other medical conditions related to social deprivation can obscure the diagnosis, and some subjects may have difficulty in expressing the symptoms which might trigger consideration of OSA as a diagnosis.

Cross sectional studies of this type can never establish a cause and effect between a diagnosis such as OSA and even closely correlated features such as a raised $\mathrm{BMI}$, but the findings should make all primary care clinicians consider OSA when dealing with obese subjects. Conversely, strenuous attempts to reduce the BMI should be made once the diagnosis of OSA has been established. This survey highlights the importance of clinicians being aware of the difficulties in diagnosing OSA in certain patient groups - especially the elderly, women, and those in low socioeconomic groups. ${ }^{1}$ The epidemic of obesity in almost all developing countries makes Wall and colleagues' findings relevant to almost every medical practitioner who treats adult patients.

Conflicts of interest The author declares that he has no conflicts of interest in relation to this article.

Commissioned article; not externally peer-reviewed; accepted 1st November 2012; online 22nd November 2012

(C) 2012 Primary Care Respiratory Society UK. All rights reserved http://dx.doi.org/10.4104/pcrj.2012.00096

Prim Care Respir J 2012: 21(4): 362-363

\section{References}

1. Wall H, Smith C, Hubbard R. BMI and obstructive sleep apnoea in the UK: a crosssectional study of the over-50s. Prim Care Respir J 2012;21(4):371-6. http://dx.doi.org/10.4104/pcrj.2012.00053

2. Young T, Palta M, Dempse J, et al. The occurrence of sleep-disordered breathing in middle-aged adults. N Engl J Med 1993;328:1230-5.

3. Gold AR, Dipalo F, Gold MS, O'Hearn D. Symptoms and Signs of Upper Airway Resistance Syndrome: a link to the Functional Somatic Syndromes. Chest 2003; 123:87-95.

4. Katz I, Stradling J, Slutsky A S, et al. Do Patients with Obstructive Sleep Apnea have Thick Necks? Am Rev Respir Dis 1990;141:1228-31.

5. Strobel R J, Rosen R C. Obesity and Weight Loss in Obstructive Sleep Apnea: A Critical Review. Sleep 1996;19:104-15.

6. Khan M, Wood K L, Bhatt N Y. Obesity Hypoventilation Syndrome. Sleep Medicine Clincs 2008;3:525-39.

7. Young T, Shahar E, Nieto F J, et al. Predictors of Sleep-Disordered Breathing in Community Dwelling Adults: The Sleep Heart and Health Study. Arch Inter Med 2002;162:893-900

8. Stone K L, Redline S, Sleep-Related Breathing Disorders in the Elderly. Sleep Medicine Clinics 2006;1:247-62

9. Bixler E O, Vgontzas AN, Ten Have T, et al. The Effects of Age on Sleep Apnea in Men. 1 Prevalence and Severity. Am J Respir Crit Care Med 1998;157:144-8. 